\title{
Determination and Improvement of the Postharvest Storability of Little Mallow (Malva Parviflora L.): A Novel Crop for a Sustainable Diet
}

\author{
İbrahim Kahramanoğlu \\ Department of Horticultural Production and Marketing, Faculty of \\ Agricultural Sciences and Technologies, European University of Lefke, \\ Northern Cyprus, via Mersin 10 Turkey, 99780
}

Chunpeng Wan

Jiangxi Key Laboratory for Postharvest Technology and Nondestructive Testing of Fruits and Vegetables/ Collaborative Innovation Center of Postharvest Key Technology and Quality Safety of Fruits and Vegetables in Jiangxi Province, College of Agronomy, Jiangxi Agricultural University, Nanchang 330045, China

Additional index words. arabic gum, hot water dipping, low-density polyethylene, polypropylene, rosemary leaf extracts

\begin{abstract}
Little mallow (Malva parviflora $\mathrm{L}$.) has been traditionally used as an alternative food source. To the authors' knowledge, there is no available published information about the postharvest storability of little mallow. This study was conducted in three steps. It aimed to determine the postharvest storability of little mallow leaves and to improve its storability using different strategies. First, the effects of four different storage conditions on the storability of little mallow leaves were tested to determine the most favorable conditions for further studies: $5 \pm 1{ }^{\circ} \mathrm{C}$ and $95 \%$ relative humidity (RH); $9 \pm 1{ }^{\circ} \mathrm{C}$ and 95\% RH; $13 \pm 1^{\circ} \mathrm{C}$ and $95 \% \mathrm{RH}$; and $24 \pm 1^{\circ} \mathrm{C}$ and 55\% RH as control. Preliminary experiments suggested that the best temperature and $\mathrm{RH}$ combination is $9 \pm 1{ }^{\circ} \mathrm{C}$ and 95\% RH. Hence, the effects of hot water dipping (HWD) were tested at three different temperatures $\left(40,45\right.$, and $\left.50{ }^{\circ} \mathrm{C}\right)$ for two different durations (60 and 120 seconds); the results suggested that the $40{ }^{\circ} \mathrm{C}$ treatment is the most suitable heat treatment for improving the storability of mallow. The final experiments were conducted with 15 different treatments, including HWD, eco-friendly edible bio-materials, modified atmosphere packaging, and ultraviolet radiation. Results showed that low-density polyethylene (LDPE) $(60 \times 60 \mathrm{~cm}$; thickness, $50 \mu)$ and polypropylene $(P P)(35 \times 50 \mathrm{~cm}$; thickness, $35 \mu)$ packaging provide the highest efficacy for preserving overall quality. The edible quality of little mallow can be extended to 15 days with PP and 12 days with LDPE. However, both materials caused an abnormal odor after that time. Further studies involving additional edible coatings are necessary to determine if the storage duration of little mallow leaves could be extended.
\end{abstract}

The world is facing a big challenge because it is becoming increasingly urbanized and the human population is continuously growing worldwide (FAO, 2020). The available resources, especially water (Kang et al., 2009) and soil (Zhang et al., 2020), for food production are being depleted due to damage to the environment caused by human activities (Kahramanoğlu, 2017). According to the FAO (2020), $\approx 821.6$ million people (nearly $10.8 \%$ of the whole population) were under-

Received for publication 27 May 2020. Accepted for publication 16 June 2020 .

Published online 20 July 2020.

C.W. is the corresponding author. E-mail: chunpengwan@ jxau.edu.cn.

This is an open access article distributed under the CC BY-NC-ND license (https://creativecommons. org/licenses/by-nc-nd/4.0/).
Report, 2017). The number of edible plants is estimated to be $\approx 30,000$ (Warren, 2015; Food Plant Solutions, 2016); of these, only $\approx 150$ have been commercialized as crops (Sethi, 2015). Only 12 of these $\approx 150$ provide three-quarters of the world's food energy intake, and only three (rice, maize, and wheat) of these 12 comprise approximately two-thirds of that intake (IRDC, 2010). Therefore, the introduction of other edible crops to domestication (production and consumption) is highly beneficial to achieving a sustainable diet and food security on Earth. Diversification of crop production might help to achieve sustainable agro ecosystems, reduce input use, improve food supply, and increase the crops consumed. The Mediterranean region is known to have rich biodiversity, and most of the plants species there are classified as wild relatives of crops (Barazani et al., 2008). Species belonging to the Malva spp. Are reported to have a rich history in the Mediterranean diet (Bouriche et al., 2011). A recent study by Ben-Simchon et al. (2019) documented that some varieties of Malva species (Malva nicaeensis and Lavatera cretica) are comparable to similar green vegetables (wild beet, Turkish spinach, Rumex spp., and New Zealand spinach) and are very good candidates for food crops, even though their high levels of nitrates were concerning (Cooper and Johnson, 1984). The scientific world has turned to alternative edible crops, especially the ones that are highly adaptable to current climatic conditions, and further studies are ongoing. The leaves of different Malva species are known to have high levels of vitamins A, C, and E, carotene, phenolic compounds, flavonoids, terpenoids, mucilage, fiber, essential fatty acids, and some minerals (i.e., calcium and potassium) (Yarijani et al., 2019). Mallows have a long history of medicinal use because of their high antioxidant activity and antiinflammatory potential (Bilen et al., 2019; Martins et al., 2017). Little mallow plant (Malva parviflora L.) is among the edible crops and has been part of the Mediterranean diet for a long time. However, there is no available information about its postharvest storability. Existing available information recommends that hot water dipping (HWD) is a successful method of improving the storability of vegetables (Glowacz et al., 2013). Moreover, modified atmosphere packaging (MAP) was extensively tested on numerous fruits and vegetables, including broccoli (Artes et al., 2001), cabbage (Plestenjak et al., 2008), cucumber (Kahramanoğlu and Usanmaz, 2019), and spinach (Allende et al., 2006), and it had high potential to maintain the postharvest quality of vegetables. Some other important eco-friendly alternatives for the improvement of postharvest storability of fresh crops are light irradiation (Papoutsis et al., 2019), plant extracts (Chen et al., 2019; Xin et al., 2019), edible films and coatings (Ncama et al., 2018; Riva et al., 2020), essential oils (Kahramanoğlu, 2019; Prakash et al., 2015), chitosan (Gutiérrez-Martínez et al., 2018), and propolis (Kahramanoğlu et al., 2018). 
Therefore, the present study was conducted to determine the postharvest storability of little mallow and to test the effects of some eco-friendly and human safety methods of improving the postharvest storability of little mallow. Studies were divided into three phases. During the first step, the optimum temperature and relative humidity $(\mathrm{RH})$ conditions were tested. Then, the effects of HWD on the postharvest quality and storability of little mallow were determined. Finally, the effects of different treatments, including lowdensity polyethylene (LDPE) and polypropylene (PP) packaging, HWD, rosemary leaf extracts, HWD with rosemary leaf extracts (RLEX), sodium bicarbonate, arabic gum, and ultraviolet-blacklight blue (BLB), on the postharvest storability of little mallow were tested.

\section{Materials and Methods}

Plant materials. Freshly harvested little mallow (Malva parviflora L.) crops were used in the present study. Crops were collected from rows of a citrus orchard located in Baglikoy, Lefke province, in Northern Cyprus during Jan. and Feb. 2020 (preliminary and further experiments). The area where the plants were collected was characterized by a Mediterranean climate. The main characteristics of the climate are mild and rainy winters and hot and dry summers. The mean yearly rainfall of the area is $\approx 380 \mathrm{~mm}$. The average minimum and average maximum temperatures during January and February were noted as 6.85 and 16.07 and 7.79 and 17.54 , respectively. The soil was clay loam with a $\mathrm{pH}$ of 7.7 and $2.2 \%$ organic matter. Neither herbicides nor insecticides were used in the selected citrus orchard during the growing season. The crops were harvested from the base of soil $(\approx 50 \mathrm{~cm})$, and the first $5 \mathrm{~cm}$ from the bottom were immediately immersed in water to prevent water loss and shriveling. The crops were transported to the laboratory within $1 \mathrm{~h}$. Then, crops were selected if they had good appearance and no pest damage. They were all cut to $\approx 30 \mathrm{~cm}$ from top.

Preliminary studies. A literature search showed no studies of the storage conditions (temperature and $\mathrm{RH}$ ) of little mallow. Therefore, preliminary studies were conducted to determine the most suitable temperature and RH combination. Studies involving similar crops (with similar characteristics with little mallow) were used to determine the test conditions. Such studies reported $5{ }^{\circ} \mathrm{C}$ for spinach (Martínez-Sánchez et al., 2019), $20{ }^{\circ} \mathrm{C}$ for vegetable amaranth (Gogo et al., 2018), and 4 and $23{ }^{\circ} \mathrm{C}$ for spinach (Grozeff et al., 2013). Therefore, the test storage conditions were determined to be: 1) $5 \pm 1{ }^{\circ} \mathrm{C}$ and $95 \% \mathrm{RH}$; 2) $9 \pm 1{ }^{\circ} \mathrm{C}$ and $95 \% \mathrm{RH}$; 3) $13 \pm$ $1{ }^{\circ} \mathrm{C}$ and $95 \% \mathrm{RH}$; and 4) $24 \pm 1{ }^{\circ} \mathrm{C}$ and $55 \%$ $\mathrm{RH}$ (as control).

Preliminary studies were conducted to evaluate the preservation effects of different temperatures and RH on weight loss and shriveling. The study design of the treatments was a completely randomized design (CRD) with five replications, and each replication was formed from a bunch of five crops (each $\approx 30$ ). The total weight of five crops was $\approx 105 \mathrm{~g}$, (range, 96.90-113.85 g). After harvest, crops were bunched together and directly transferred to the aforementioned storage conditions. Studies were continued for $12 \mathrm{~d}$ and quality measurements were performed at 3-days interval. The initial weights of all the bunches were measured and noted at the beginning of the studies. At the aforementioned times $(3,6,9$, and $12 \mathrm{~d})$, the final weights of the bunches were measured and used to calculate weight loss. A digital scale $( \pm 0.01 \mathrm{~g})$ was used to measure the weights. Shriveling of the leaves was assessed according to a scale from 1 to 5 (Table 1). Preliminary studies suggested that the best temperature and $\mathrm{RH}$ combination is $9 \pm 1{ }^{\circ} \mathrm{C}$ and $95 \% \mathrm{RH}$ for the little mallow. Further studies were continued with this temperature.

Second studies. Second studies were conducted to determine the effects of HWD on the storage quality of little mallow. HWD is a well-known strategy of preserving the postharvest storage quality of fruit crops, such as mandarins (Kahramanoğlu et al., 2020), and was also successful for the storage of spinach (Glowacz et al., 2013). During the determination of the test temperatures for the present study, all of the aforementioned studies were considered but highly influenced by the research of Glowacz et al. (2013), who tested HWD at three different temperatures $(40,45$, and $\left.50{ }^{\circ} \mathrm{C}\right)$ and three different durations $(30$, 60 , and $120 \mathrm{~s}$ ). Therefore, the present study tested three different HWD temperatures (40,
45 , and $50^{\circ} \mathrm{C}$ ), and these three temperatures were tested for $1 \mathrm{~min}$ and 2 min, separately. A similar procedure was followed during the preliminary studies, and five replications were used for each treatment. In addition to the HWD treatments, a control treatment was added to the studies and a bunch of little mallow fruits were dipped in normal water (at room temperature $25{ }^{\circ} \mathrm{C}$ for $1 \mathrm{~min}$ ). The plants were arranged in the cold rooms according to the CRD experimental procedure. All of the leaves treated with different HWD and control were stored at $9 \pm 1{ }^{\circ} \mathrm{C}$ and $95 \% \mathrm{RH}$, which were best for the preliminary studies. Similar to the preliminary studies, experiments were continued for $12 \mathrm{~d}$ and quality characteristics (weight loss and shriveling) were assessed at days 3, 6, 9, and 12 of storage. Results suggested that $40{ }^{\circ} \mathrm{C}$ is best for the mallow's storability compared with other treatments and control. The final experiments were conducted with 15 different treatments, including $40{ }^{\circ} \mathrm{C}$ HWD.

Final studies. After the second studies, the final studies were designed to test different treatments, including MAP, HWD, HWD plus RLEX, sodium bicarbonate, arabic gum, and ultraviolet-B light source (Table 2). Reasons for and justification of the test of treatments in present study can be summarized as follows. The two materials used during the present study, low-density polyethylene (LDPE) and PP, are among the packaging materials used in MAP. In this study, RLEX were also incorporated in HWD and tested together. Moreover, RLEX, which are known to control postharvest spoilage, were tested (Nikkhah and Hashemi, 2020). Sodium bicarbonate was also previously tested and was effective for preventing the development of postharvest diseases (Lai et al., 2015). Therefore, sodium bicarbonate and arabic gum (a well-known edible coating) were selected in the present study to test on little mallow. The final test material of the present study was ultravioletBLB. Ultraviolet-B was previously tested on fresh-cut spinach leaves, and treatment for 6 min was reported to effectively protect the storage quality (Kasim and Kasim, 2017).

The number of replications and storage conditions were same as those in the second studies; however, the studies were continued for $21 \mathrm{~d}$, and quality measurements were performed at 3-d interval. During the final studies, in addition to weight loss and

Table 1. Definition of the visual quality and shriveling scores used in the present study.

\begin{tabular}{|c|c|c|c|c|c|c|}
\hline \multirow{2}{*}{ Quality } & \multicolumn{5}{|c|}{ Scale scores } & \multirow{2}{*}{ Reference for scale } \\
\hline & 1 & 2 & 3 & 4 & 5 & \\
\hline $\begin{array}{l}\text { Visual } \\
\text { quality }\end{array}$ & $\begin{array}{l}\text { Extremely soft, } \\
\text { does not snap, } \\
\text { very severe } \\
\text { blemishes, } \\
\text { widespread } \\
\text { microorganism } \\
\text { attack }\end{array}$ & $\begin{array}{l}\text { Soft, bends easily, } \\
\quad \text { does not snap, } 51 \% \\
\text { to } 75 \% \text { dryness, } \\
\text { severe blemishes, } \\
\text { microorganism } \\
\text { attack }\end{array}$ & $\begin{array}{l}\text { Tender but less firm, } \\
\text { does not snap easily, } \\
25 \% \text { to } 50 \% \text { dryness, } \\
\text { moderate blemishes }\end{array}$ & $\begin{array}{l}\text { Tender and firm, } \\
\text { snaps easily, } 1 \% \\
\text { to } 25 \% \text { dryness, } \\
\text { minor blemishes }\end{array}$ & $\begin{array}{l}\text { Extremely tender } \\
\text { and firm, snaps } \\
\text { very easily, less } \\
\text { than } 1 \% \text { of dents, } \\
\text { absence of blemishes, } \\
\text { and absence of } \\
\text { microorganism attack }\end{array}$ & $\begin{array}{l}\text { Modified from } \\
\text { Silvia et al. } \\
\text { (2015) }\end{array}$ \\
\hline
\end{tabular}


Table 2. Full list and descriptions of the 15 treatments tested during the final studies.

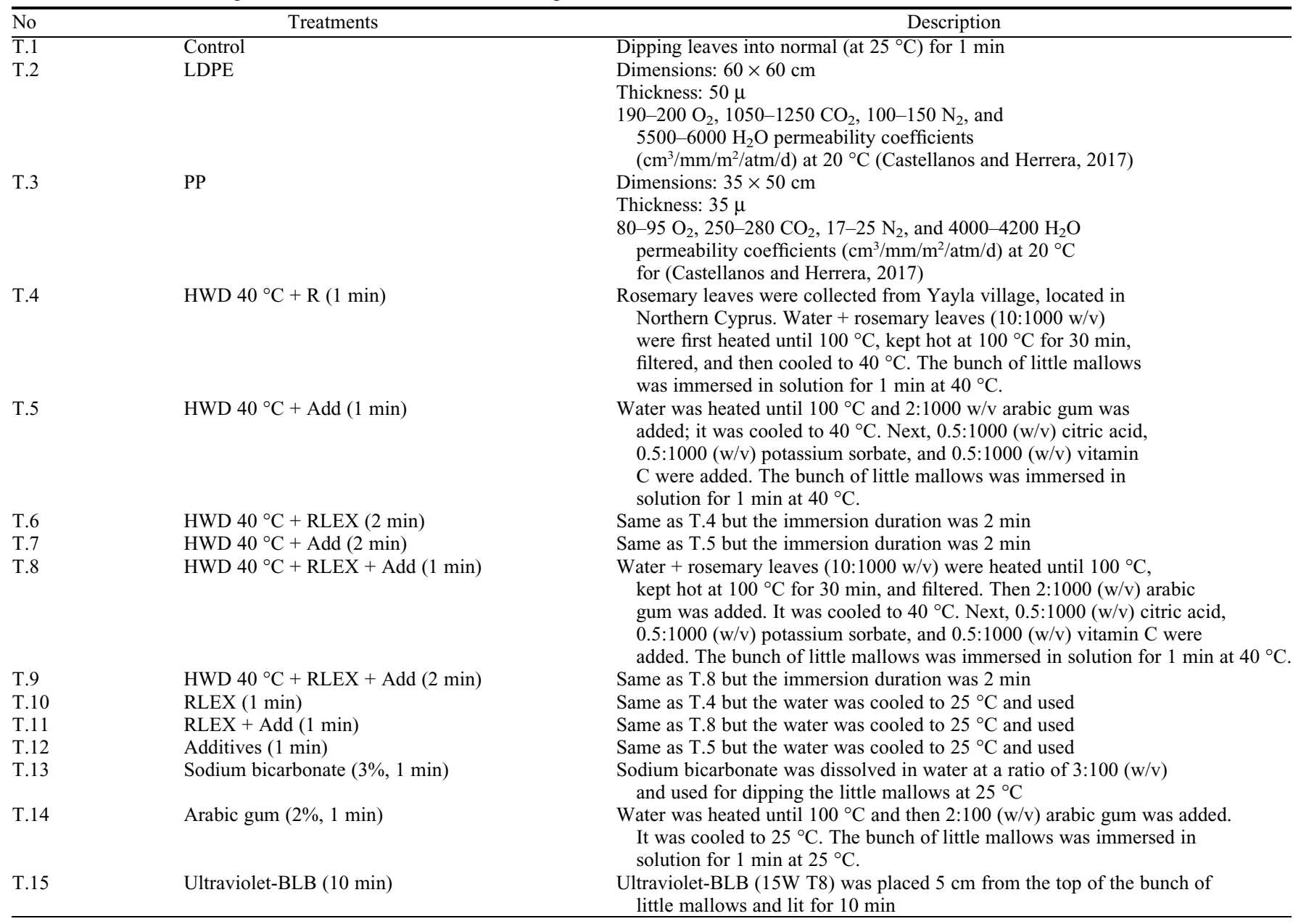

BLB = blacklight blue; RH = relative humidity; LDPE = low-density polyethylene; PP = polypropylene; HWD = hot water dipping; RLEX = rosemary leaf extract; $\mathrm{R}=$ rosemary; $\mathrm{T}=$ treatment.

shriveling, visual quality, abnormal odor, decay incidence, ascorbic acid (AsA) (vita$\min \mathrm{C})$, respiration rate, chlorophyll content, and carotenoids contents were also determined. Visual quality was assessed according to the scale (Table 1).

Odor intensity and pleasantness were observed according to the $0-10$ scale reported by Han et al. (2020), where 0 represents extremely pleasant and 10 represents very strongly perceived and extremely unpleasant leaves. Moreover, the decay incidence of the little mallows was observed by using the $0-3$ scale reported by Cao et al. (2011), where 0 represents no decay, 1 represents slight decay $(\leq 25 \%), 2$ represents moderate decay $(25 \%$ to $<50 \%$ ), and 3 represents severe decay $(>50 \%)$. The assessment of AsA content was performed using titration with 2,6-dichlorophenol indophenols method (Kahramanoğlu et al., 2020). The respiration rate $\left(\mathrm{mL} \mathrm{CO}_{2} / \mathrm{kg} /\right.$ h) of the samples was assessed using the method of Fonseca et al. (2002). Then, the chlorophyll contents of the leaf samples were determined using the method developed by Arnon (1949) as suggested by Sudhakar et al. (2016). Furthermore, the carotenoids $\left(C_{x+c}\right.$; $\mathrm{x}=$ xanthophylls, $\mathrm{c}=$ carotenes) content was assessed according to the formula developed by Lichtenthaler and Buschmann (2001).

Data analysis. Microsoft Excel was used to summarize raw data and prepare figures to enable a better evaluation of the results. Moreover, a comparison of the effects of different treatments was performed by subjecting the data to an analysis of variance. Finally, separation of the means of different treatments was performed with Tukey's honestly significant difference multiple range test $(P=0.05)$.

\section{Results}

Determination of optimum storage temperature. Little mallow is an edible, traditional crop that comprises a large part of the Mediterranean diet. However, because it is not a commercialized crop, there have not been any studies of its postharvest storability or suitable storage conditions. The studies were continued for $12 \mathrm{~d}$, and a large amount of weight loss from the leaves was noted. According to the results obtained, storage at 5 $\pm 1{ }^{\circ} \mathrm{C}$ and $95 \% \mathrm{RH}$ and at $9 \pm 1{ }^{\circ} \mathrm{C}$ and $95 \%$ $\mathrm{RH}$ kept the weight loss at $\approx 40 \%$ at $12 \mathrm{~d}$, whereas the weight loss of the leaves stored at ambient conditions reached more than 55\% (Fig. 1). In addition to weight loss, the shriveling characteristics of the leaves were determined during storage. The results showed that reducing temperatures is highly beneficial for reducing weight loss, but it might cause an increase in shriveling. Therefore, $9 \pm 1{ }^{\circ} \mathrm{C}$ and $95 \% \mathrm{RH}$ conditions were best for storing little mallow leaves. Therefore, further studies were continued with this storage condition.

Effects of hot water dipping. According to the results, weight loss with the control treatment was close to $40 \%$ at $12 \mathrm{~d}$ of storage (Fig. 2). At that time, only HWD at $40{ }^{\circ} \mathrm{C}$ for $1 \mathrm{~min}$ resulted in less weight loss $(35.98 \%)$ compared with the control treatment. HWD at $40{ }^{\circ} \mathrm{C}$ for 2 min resulted in weight loss similar to that of the control treatment. The dipping duration was significant for HWD at $45^{\circ} \mathrm{C}$ and HWD at $50^{\circ} \mathrm{C}$. When the dipping duration was increased from $1 \mathrm{~min}$ to $2 \mathrm{~min}$, weight loss increased. The effects of HWD were also tested for shriveling (Fig. 3), and results parallel to the weight loss results were observed. The highest shriveling score was obtained with HWD at $40{ }^{\circ} \mathrm{C}$ for $1 \mathrm{~min}$ treatment at $12 \mathrm{~d}$ of storage, followed by 


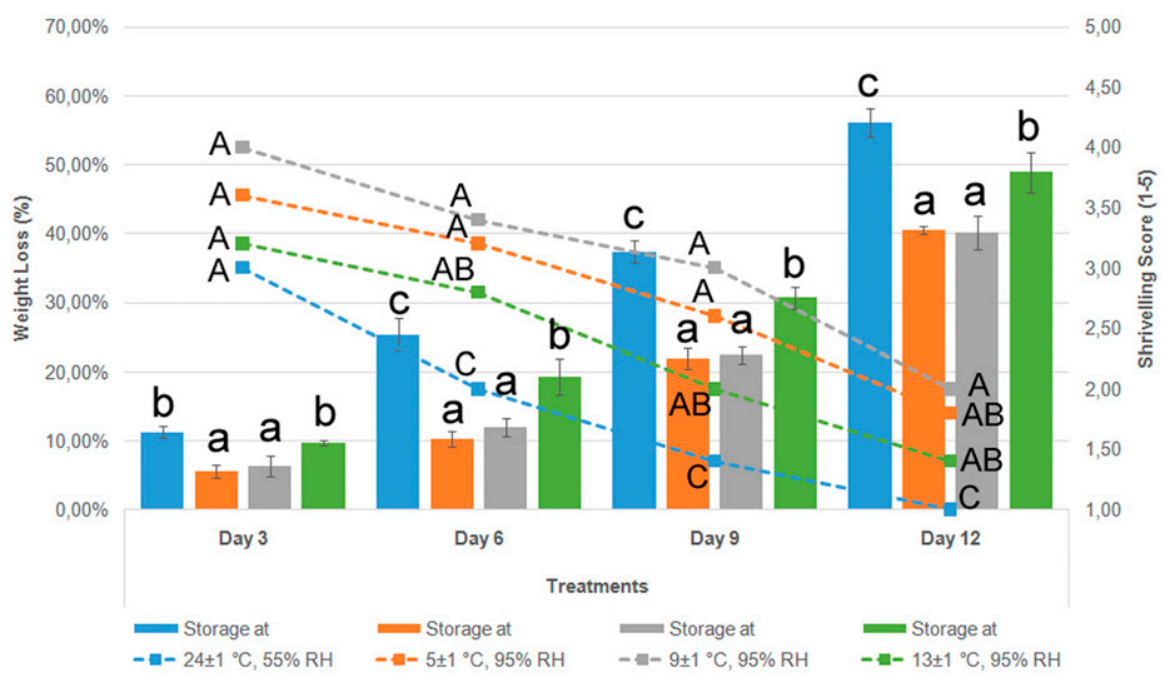

Fig. 1. Effects of different storage temperatures on the weight loss and shriveling of little mallow leaves during $12 \mathrm{~d}$ of storage. Mean separations were performed with Tukey's honestly significant difference at $P=0.05$ and values followed by the same letter or letters are not significantly different. Small letters on the bars are used to compare weight loss and capital letters near the lines are used for shriveling. The starting letter " $\mathrm{a}$ " is not used for highest numbers but rather to indicate preference.

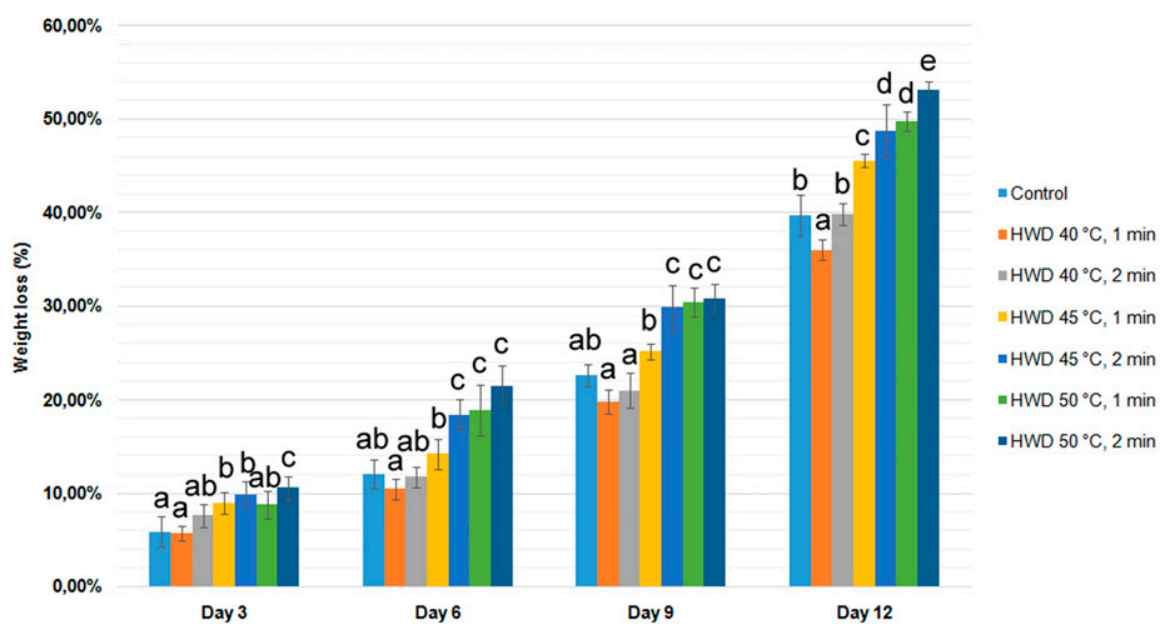

Fig. 2. Effects of different hot water dipping (HWD) temperatures and durations on weight loss of little mallow leaves during $12 \mathrm{~d}$ of storage. Mean separations were performed with Tukey's honestly significant difference at $P=0.05$ and values followed by the same letter or letters are not significantly different. Comparisons were performed separately at each measuring point. The starting letter " $\mathrm{a}$ " is not used for highest numbers but rather to indicate preference

the control and HWD at $40{ }^{\circ} \mathrm{C}$ for $2 \mathrm{~min}$ treatments. However, even the best treatments had a shriveling score less than 2.0 at $12 \mathrm{~d}$ of storage. A score of 2.0 represents poor, which is equal to serious shriveling (51\% to $75 \%)$. The other four treatments resulted in worse scores for shriveling. Overall, the results suggested that the best HWD among the test temperatures is $40{ }^{\circ} \mathrm{C}$ for $1 \mathrm{~min}$. Therefore, further studies were continued with this treatment.

Improving postharvest storability of little mallow. To improve the postharvest storability of little mallow, 14 different treatments and 1 control application were tested. The quality parameters of the stored leaves were measured with 3-d intervals for up to $21 \mathrm{~d}$ of storage. The results of the present study showed that the postharvest storability of incorporation of RLEX in HWD significantly improves its efficacy.

The shriveling and visual quality scores were similar, as were the weight loss results. The most successful treatments for protection from shriveling and visual quality were LDPE and PP. The scores of these two treatments were very high $(>4.0)$, which indicated good results. After these two treatments, HWD $40{ }^{\circ} \mathrm{C}+\operatorname{RLEX}(1 \mathrm{~min})$ treatment resulted in a score of 2.8 for both shriveling and visual quality. This score is slightly less than the acceptable limit (3.0). The best results were obtained with PP and LDPE treatments and followed by the HWD $40{ }^{\circ} \mathrm{C}+\operatorname{RLEX}(1 \mathrm{~min})$ treatment. Other treatments were ineffective for preventing decay incidence. Increasing the HWD duration reduced the effectiveness of the treatments and increased damage to the leaves. The highest odor scores, which were undesirable, were obtained when the LDPE and PP treatments were used. This might have been the result of anaerobic respiration. Further studies are required for clarification. Consequently, it can be suggested that the PP is more effective than LDPE for preserving the postharvest quality of little mallow leaves. The appearances of little mallows treated with different treatments are shown in Fig. 4.

The odor results of the current study had a reverse relationship with the respiration rate, as expected. The respiration rates of little mallow leaves were $429.26 \mathrm{~mL} \mathrm{CO} / \mathrm{kg} / \mathrm{h}$ at the time of harvest under ambient conditions and $104.62 \mathrm{~mL} \mathrm{CO} / \mathrm{kg} / \mathrm{h}$ in a cold room. On day 15 , the lowest respiration rates resulted from LDPE and PP treatments (31.88 and $32.74 \mathrm{~mL} \mathrm{CO} / \mathrm{kg} / \mathrm{h}$, respectively). However, the HWD treatments with 2-min dipping durations resulted in higher respiration rates. At the beginning of the studies, the AsA concentration of little mallow leaves was $31.56 \mathrm{mg} / 100 \mathrm{~g}$, and it decreased during storage. This reduction was higher for HWD-treated leaves and lower for leaves stored in PP and LDPE. The third highest AsA concentration resulted from the control treatment. Similar to AsA, the chlorophyll and carotenoids $\left(\mathrm{Car}_{\mathrm{x}+\mathrm{c}}\right)$ contents of the treated leaves showed a decreasing trend during storage. At that time, PP was the most effective treatment for preventing the loss of these qualities.

The present study showed that both LDPE and PP effectively preserved the postharvest storage quality of little mallows (Fig. 5C). The respiration rate of the control leaves showed a slightly increasing trend during storage. However, the leaves stored in LDPE and $\mathrm{PP}$ showed an increasing trend during storage. The trend continued to decrease for leaves stored in LDPE, but the leaves treated with PP showed an increasing trend after $12 \mathrm{~d}$ of storage. At that time, it was observed (Fig. 5B) that the $\mathrm{O}_{2}$ and $\mathrm{CO}_{2}$ concentrations were equal in the PP bags; then, the $\mathrm{O}_{2}$ concentration continued to decrease while the $\mathrm{CO}_{2}$ concentration remained stable. The $\mathrm{O}_{2}$ concentration in $\mathrm{PP}$ was $\approx 0.24 \%$ at $18 \mathrm{~d}$ 
of storage, which caused respiration to stop and might have been the main reason for the large loss of leaf quality.

\section{Discussion}

No similar studies of the optimum storage temperatures of little mallow (or other mallows) leaves were found in the published literature, but the overall results of the present study are in agreement with the general information that has been published (Kahramanoğlu, 2017). One of the most important results of the present study is that the low temperature reduces the respiration rate and prevents weight loss of little mallow leaves. Similar optimum temperature ranges were previously recommended for spinach (Tudela et al., 2013). The present study also showed that HWD is beneficial for improving the postharvest quality of little mallow and that the HWD duration is very significant. HWD has been investigated by many post- harvest studies and is widely used for the prevention of postharvest quality loss and of fungal decay (Hong et al., 2014). HWD treatment also reduced the respiration rate, which is often associated with increased storability (Kahramanoğlu et al., 2020). It has been noted that $45^{\circ} \mathrm{C}$ for $1 \mathrm{~min}$ is most effective for maintaining the postharvest quality of spinach (Glowacz et al., 2013).

The most successful treatments according to the present study are LDPE and PPE bags. They effectively reduced the respiration rate and weight loss, thereby preventing the loss of chlorophyll, carotenoids, and AsA contents of little mallow. The only negativity observed with LDPE and PP was the abnormal odor, which was suggested to be due to anaerobic respiration. MAP has been reported to successfully preserve several vegetables, including broccoli (Artes et al., 2001), cabbage (Plestenjak et al., 2008), cucumber (Kahramanoğlu and Usanmaz, 2019), and spinach (Allende et al., 2006).

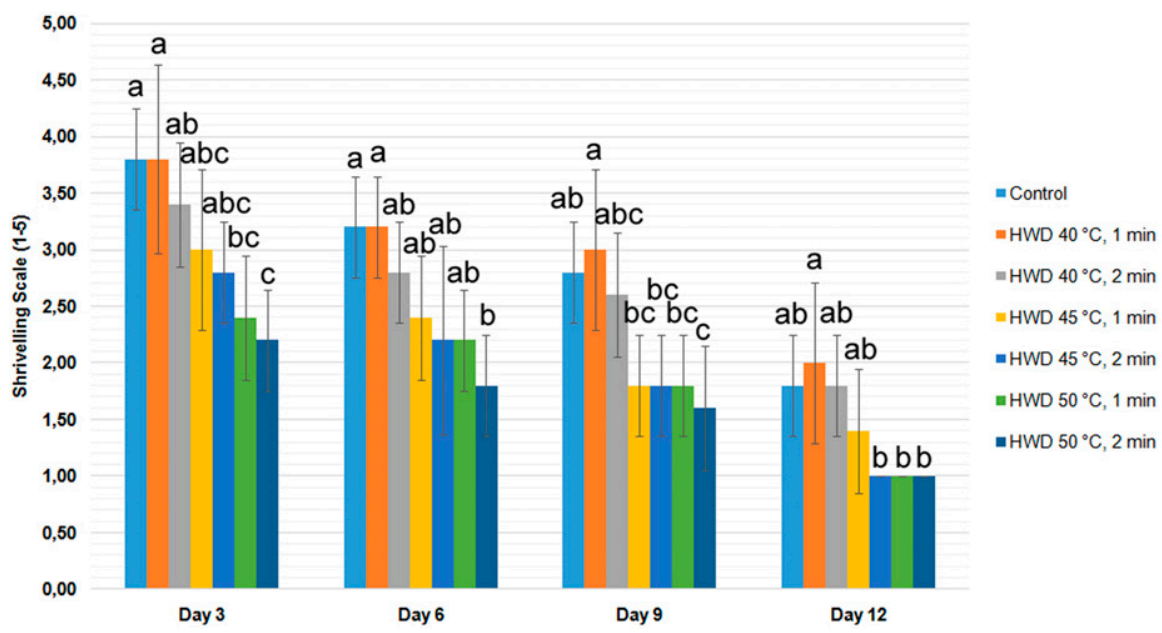

Fig. 3. Effects of different hot water dipping (HWD) temperatures and durations on the shriveling of little mallow leaves during $12 \mathrm{~d}$ of storage. Mean separations were performed with Tukey's honestly significant difference at $P=0.05$ and values followed by the same letter or letters are not significantly different. Comparisons were performed separately at each measuring point. The starting letter "a" is not used for highest numbers but for the indication of most preference)
The successful results of the present study are in agreement with those of these previous studies in which both LDPE and PP effectively preserved the postharvest storability of little mallow leaves. LDPE and PP are among the most widely used polymer films for MAP (Castellanos and Herrera, 2017). Different polymeric materials have different characteristics (due to differentiations in permeability of $\mathrm{O}_{2}, \mathrm{CO}_{2}$, and water vapor). It is important to know the specific requirements of produce to determine which material is best for that produce. PP tested in the present study has moderate permeability $\left(80-95 \mathrm{O}_{2}, 250-280\right.$ $\mathrm{CO}_{2}, 17-25 \mathrm{~N}_{2}$, and 4000-4200 $\mathrm{H}_{2} \mathrm{O} \mathrm{cm}^{3} /$ $\mathrm{mm} / \mathrm{m}^{2} / \mathrm{atm} / \mathrm{d}$ ), and LDPE has high permeability $\left(190-200 \mathrm{O}_{2}, 1050-1250 \mathrm{CO}_{2}, 100\right.$ $150 \mathrm{~N}_{2}$, and $5500-6000 \mathrm{H}_{2} \mathrm{O} \mathrm{cm} / \mathrm{mm} / \mathrm{m}^{2} /$ $\mathrm{atm} / \mathrm{d}$ ). Both effectively preserve the postharvest quality but ineffectively prevent abnormal odor. For PP, this problem seems due to the low permeability of both $\mathrm{O}_{2}$ and $\mathrm{CO}_{2}$. The $\mathrm{O}_{2}$ concentration decreased too much in the bags, and $\mathrm{CO}_{2}$ could not be transferred out and stayed in the bags. Otherwise, LDPE effectively let $\mathrm{O}_{2}$ in and let $\mathrm{CO}_{2}$ out. However, the respiration rate was higher in the LDPE bags. Consequently, it can be suggested that the combination of LDPE and PP materials might be better for adjusting the MAP system to the optimum respiration and transpiration for produce (Zhao et al., 2019).

The carotenoids content of little mallow leaves in the present study are approximately 3 -fold of the Malva sylvestris as reported by Barros et al. (2010). The chlorophyll and carotenoids contents of treated and untreated leaves showed a decreasing trend throughout the storage period, which is in agreement with other previous studies of spinach (Bunea et al., 2008; Glowacz et al., 2013). Glowacz et al. (2013) similarly reported that HWD treatment protects the carotenoids contents of stored crops. Gómez et al. (2008) previously reported similar results for spinach and suggested that $40^{\circ} \mathrm{C}$, as in the present study, is best for improving the postharvest storability.

The total AsA concentration of little mallow leaves had a declining trend during

Table 3. Effects of 15 different treatments on weight loss, shriveling, visual quality, decay incidence, and odor during $15 \mathrm{~d}$ of storage at $9 \pm 1{ }^{\circ} \mathrm{C}$ and $95 \%$ RH.

\begin{tabular}{|c|c|c|c|c|c|}
\hline Treatments & Wt loss $(\%)$ & Shriveling (1-5) & Visual quality $(1-5)$ & Decay incidence $(0-3)$ & Odor $(1-10)$ \\
\hline Control & $45.24 \mathrm{fg}$ & $1.00 \mathrm{~d}$ & $1.40 \mathrm{~cd}$ & $1.60 \mathrm{c}$ & $4.60 \mathrm{def}$ \\
\hline PP & $1.72 \mathrm{a}$ & $4.40 \mathrm{a}$ & $4.60 \mathrm{a}$ & $0.00 \mathrm{a}$ & $4.60 \mathrm{def}$ \\
\hline $\operatorname{HWD} 40^{\circ} \mathrm{C}+\operatorname{RLEX}(1 \mathrm{~min})$ & $32.90 \mathrm{~b}$ & $2.80 \mathrm{~b}$ & $2.80 \mathrm{~b}$ & $0.40 \mathrm{ab}$ & $2.20 \mathrm{a}$ \\
\hline $\operatorname{HWD} 40^{\circ} \mathrm{C}+\operatorname{RLEX}(2 \mathrm{~min})$ & $44.00 \mathrm{efg}$ & $1.00 \mathrm{~d}$ & $1.00 \mathrm{~d}$ & $2.40 \mathrm{c}$ & $4.80 \mathrm{ef}$ \\
\hline $\operatorname{HWD} 40^{\circ} \mathrm{C}+\operatorname{Add}(2 \mathrm{~min})$ & $46.23 \mathrm{~g}$ & $1.00 \mathrm{~d}$ & $1.00 \mathrm{~d}$ & $2.40 \mathrm{c}$ & $5.60 \mathrm{f}$ \\
\hline $\operatorname{HWD} 40^{\circ} \mathrm{C}+\operatorname{RLEX}+\operatorname{Add}(1 \mathrm{~min})$ & $33.12 \mathrm{~b}$ & $2.20 \mathrm{bc}$ & $2.20 \mathrm{bc}$ & $1.40 \mathrm{bc}$ & $2.60 \mathrm{ab}$ \\
\hline RLEX + Additives (1 min) & 40.96 cde & $1.40 \mathrm{~cd}$ & $1.40 \mathrm{~cd}$ & $1.40 \mathrm{bc}$ & $4.60 \mathrm{def}$ \\
\hline Additives ( $1 \mathrm{~min})$ & $44.44 \mathrm{fg}$ & $1.40 \mathrm{~cd}$ & $1.40 \mathrm{~cd}$ & $1.60 \mathrm{c}$ & $4.60 \mathrm{def}$ \\
\hline Sodium bicarbonate $(3 \%, 1 \mathrm{~min})$ & $42.18 \mathrm{def}$ & $1.40 \mathrm{~cd}$ & $1.40 \mathrm{~cd}$ & $1.40 \mathrm{bc}$ & $3.00 \mathrm{abc}$ \\
\hline Arabic gum $(2 \%, 1 \mathrm{~min})$ & $37.94 \mathrm{c}$ & $1.80 \mathrm{bcd}$ & $1.80 \mathrm{bcd}$ & $1.40 \mathrm{bc}$ & $3.60 \mathrm{abcd}$ \\
\hline ultraviolet-BLB (10 $\mathrm{min})$ & $50.12 \mathrm{e}$ & $1.40 \mathrm{~cd}$ & $1.40 \mathrm{~cd}$ & $1.60 \mathrm{c}$ & $4.20 \mathrm{cdef}$ \\
\hline
\end{tabular}

$\mathrm{BLB}=$ blacklight blue; $\mathrm{RH}=$ relative humidity; LDPE = low-density polyethylene; $\mathrm{PP}=$ polypropylene; HWD $=$ hot water dipping; RLEX $=$ rosemary leaf extract; $\mathrm{R}=$ rosemary; $\mathrm{T}$ = treatment.

Mean separations in each column were separately performed with Tukey's honestly significant difference at $P=0.05$. Values followed by the same letter or letters are not significantly different. The starting letter " $\mathrm{a}$ " is not used for the highest numbers but rather to indicate preference. Bold number(s) in each column represents the best treatment(s) for that quality parameter. 
Table 4. Effects of 15 different treatments on the respiration rate (RR), ascorbic acid, chlorophyll content (Chl), and carotenoids content (Car $\left.r_{x+c}\right)$ during $15 \mathrm{~d}$ of storage at $9 \pm 1{ }^{\circ} \mathrm{C}$ and $95 \% \mathrm{RH}$.

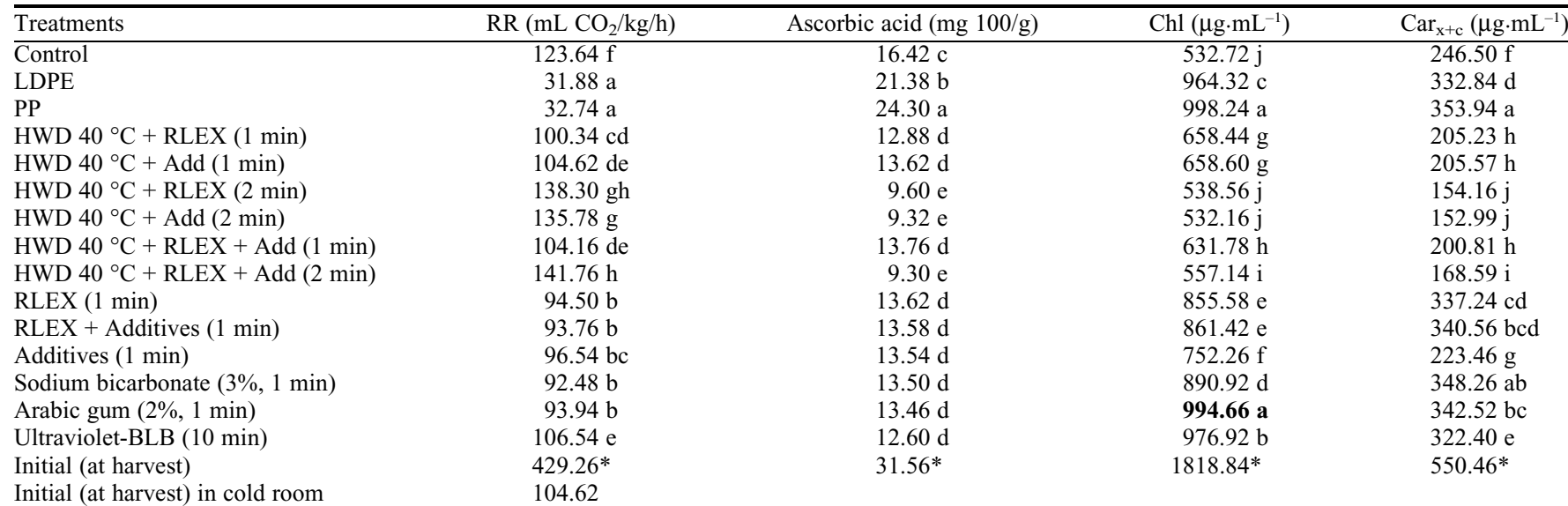

Initial (at harvest) in cold room

104.62

BLB = blacklight blue; RH = relative humidity; $\mathrm{LDPE}=$ low-density polyethylene; $\mathrm{PP}=$ polypropylene; $\mathrm{HWD}=$ hot water dipping; RLEX $=$ rosemary leaf extract.

Mean separations in each column (except initial values) were separately performed with Tukey's honestly significant difference at $P=0.05$. Values followed by the same letter or letters are not significantly different. All values were also compared with the initial (at harvest) values with a $t$ test $(P=0.05) *$ Significant differences. NS Nonsignificance. The starting letter "a" is not used for the highest numbers but rather to indicate preference. Bold number(s) in each column represents the best treatment(s) for that quality parameter.

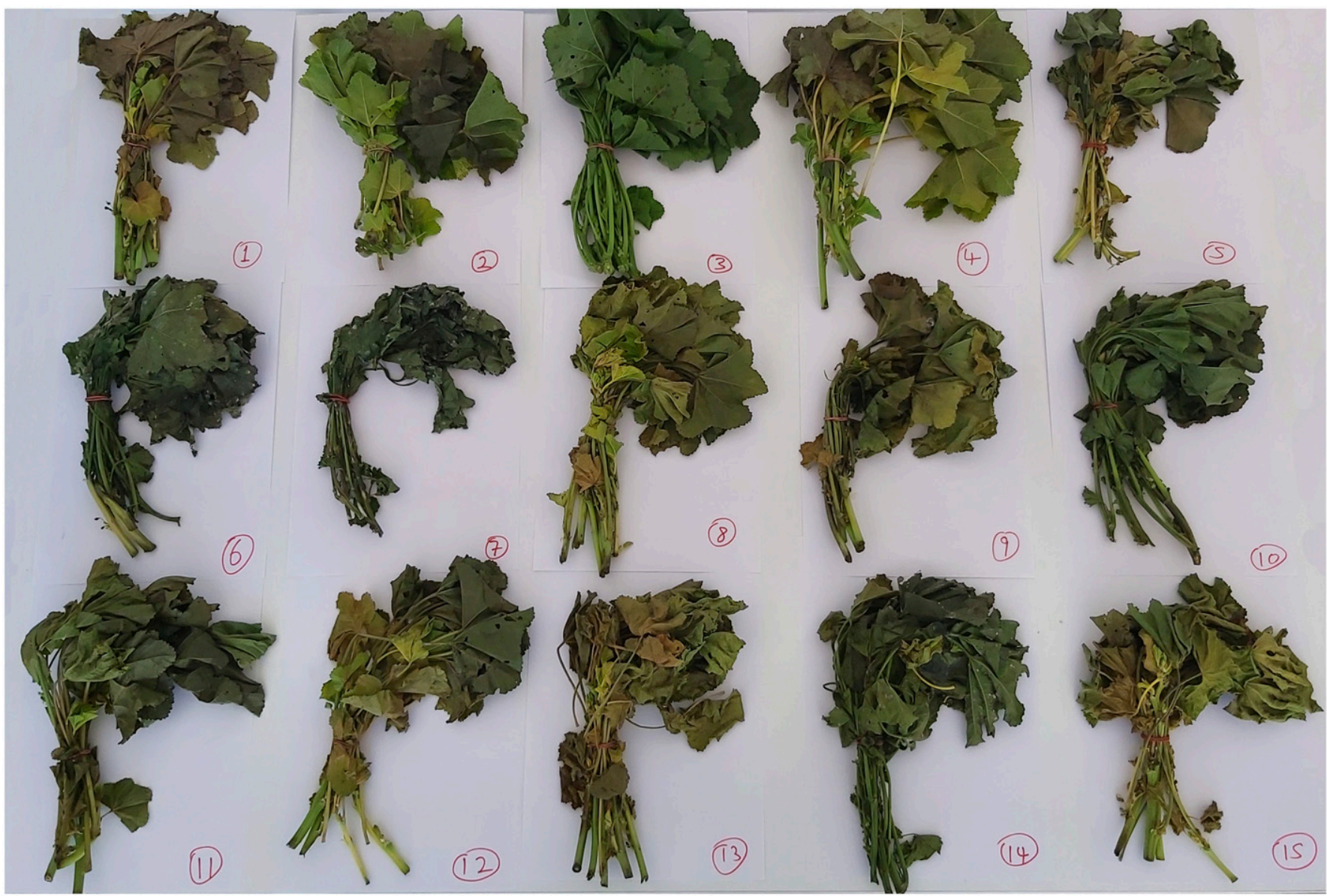

Fig. 4. Appearance of control and treated little mallows $15 \mathrm{~d}$ after storage. 1: Control; 2: Low-density polyethylene (LDPE); 3: Polypropylene (PP); 4: Hot water dipping (HWD) $40{ }^{\circ} \mathrm{C}+$ rosemary leaf extract $(\mathrm{RLEX})(1 \mathrm{~min}) ; \mathbf{5}$ : $\mathrm{HWD} 40^{\circ} \mathrm{C}+\operatorname{Add}(1 \mathrm{~min}) ; \mathbf{6}$ : HWD $40{ }^{\circ} \mathrm{C}+\operatorname{RLEX}(2 \mathrm{~min}) ; 7: \mathrm{HWD} 40{ }^{\circ} \mathrm{C}+\mathrm{Add}(2 \mathrm{~min}) ;$ 8: HWD $40^{\circ} \mathrm{C}+\operatorname{RLEX}+\operatorname{Add}(1 \mathrm{~min}) ; \mathbf{9}$ : HWD $40^{\circ} \mathrm{C}+$ RLEX + Add ( $\left.2 \mathrm{~min}\right) ; 1$ 10: Rosemary (1 min); 11: Rosemary + Add (1 min); 12: Additives (1 min); 13: Sodium bicarbonate (1 min); 14: Arabic gum (1 min); and 15: ultraviolet-blacklight blue (BLB) $(10 \mathrm{~min})$.

storage, which is in conjunction with previous findings (Bottino et al., 2009). However, HWD treatment was previously reported to increase the AsA concentration in tomato fruits (Imahori et al., 2016), but it is also

HortScience Vol. 55(8) August 2020 known that AsA is a water-soluble compound. The present result also clarify the significance of the HWD duration; the significance of the duration was previously reported for Satsuma mandarins by Shen et al.,
(2012). Incorporating RLEX into HWD was performed to increase its efficacy, as suggested for other bio-materials by Hong et al. (2014). In fact, the incorporation of RLEX into HWD did improve the positive effects of 

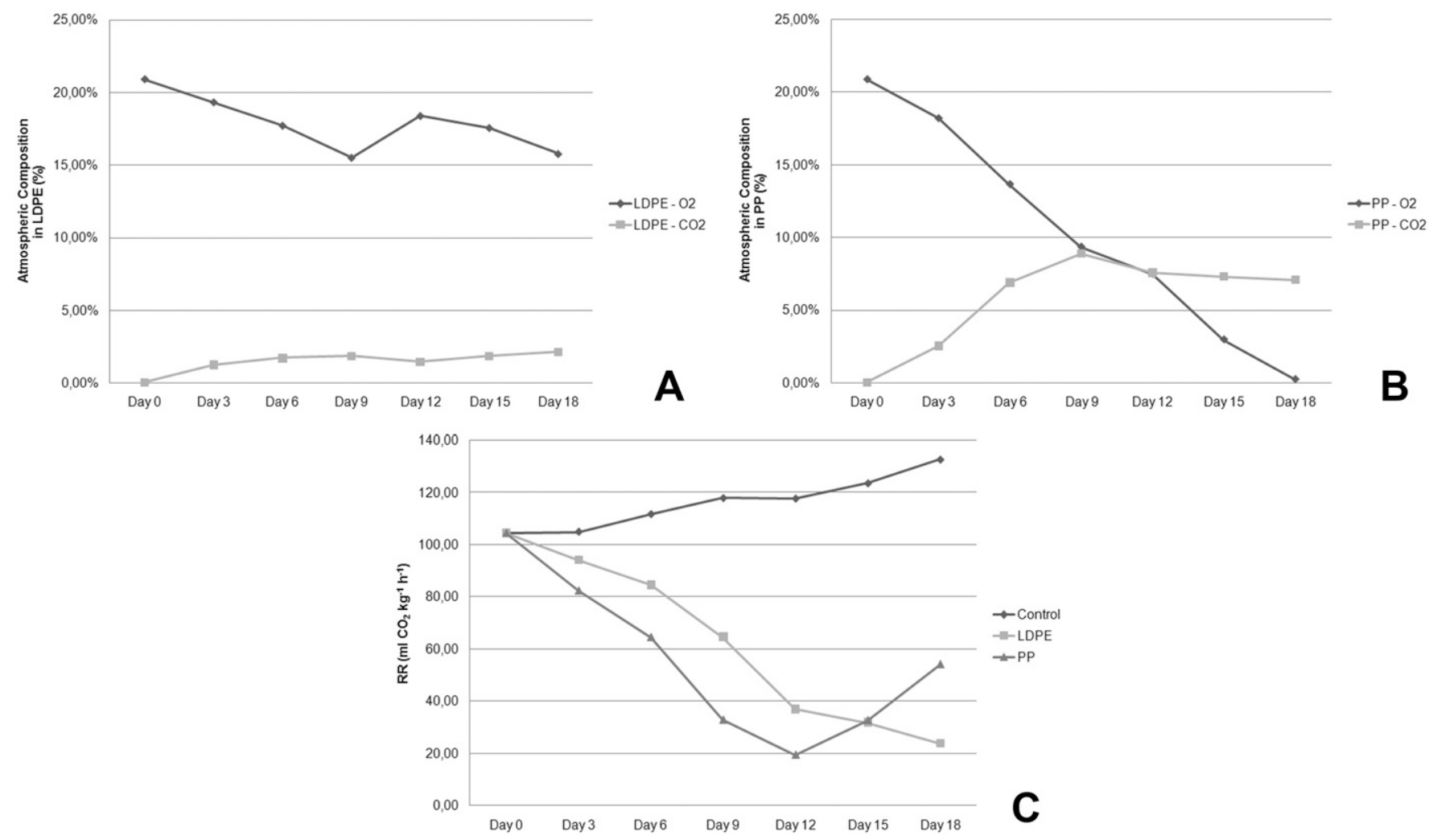

Fig. 5. Changes in the atmospheric composition $\left(\mathrm{CO}_{2}\right.$ and $\left.\mathrm{O}_{2}\right)$ in the (A) low-density polyethylene (LDPE) and (B) polypropylene (PP) bags and the relationship between $(\mathbf{C})$ the respiration rate of little mallow leaves during $21 \mathrm{~d}$ of storage.

treatment. Similarly, rosemary oil was also noted to have high antimicrobial activity (Garcia-Sotelo et al., 2019).

In the present study, arabic gum was used in HWD as an additive and alone. Arabic gum is among the most used polysaccharides in the industrial sector (Motlagh et al., 2006). Both arabic gum and sodium bicarbonate effectively reduced the respiration rate and prevented the loss of chlorophyll and carotenoids. However, overall, they did not effectively prevent weight loss. Similar success with arabic gum was previously reported (Ali et al., 2010). The results of preventing carotenoids loss using arabic gum are in agreement with the findings of Ali et al. (2013). Ultraviolet radiation applications are among the recently developed treatments used for preventing decay and extending the storability of vegetables. Among the ultraviolet applications, ultraviolet-C is the most used, and successful results have been reported for beans (Kasim and Kasim, 2008) and spinach (Escalone et al., 2010). However, the results of the present study are not in agreement with previous results that indicated that ultraviolet-B did not effectively protect the postharvest quality. However, exposure to ultraviolet-B has been reported to generate different responses in different plants (Yao et al., 2006). Although it did not effectively prevent the postharvest storage quality, ultraviolet-B protected from the loss of carotenoids (Aguiló-Aguayo et al., 2013). Further studies of different doses and applications of arabic gum, sodium bicarbonate, and
ultraviolet-B could provide better information regarding how to maintain the postharvest storability of little mallow.

\section{Conclusions}

Based on the three-steps studies, the optimum temperature and $\mathrm{RH}$ combination for little mallow leaves is $9 \pm 1{ }^{\circ} \mathrm{C}$ and $95 \% \mathrm{RH}$. Higher temperatures $\left(45\right.$ and $\left.50{ }^{\circ} \mathrm{C}\right)$ and longer durations ( $2 \mathrm{~min}$ ) of HWD cause damage to little mallow leaves. Therefore, $\mathrm{HWD}$ at $40{ }^{\circ} \mathrm{C}$ for $1 \mathrm{~min}$ is more effective. The incorporation of RLEX into HWD applications improves its efficacy and prolongs the storage duration of little mallow. LDPE and PP have the highest significant influence on improvements in postharvest storability of little mallow leaves. The combination of LDPE and PP materials might help adjust the MAP system to achieve the optimum respiration and transpiration; however, further studies are required for clarification.

\section{Literature Cited}

Aguiló-Aguayo, I., F. Charles, C.M.G.C. Renard, D. Page, and F. Carlin. 2013. Pulsed light effects on surface decontamination, physical qualities and nutritional composition of tomato fruit. Postharvest Biol. Technol. 86:29-36.

Ali, A., M. Maqbool, P.G. Alderson, and N. Zahid. 2013. Effect of gum arabic as an edible coating on antioxidant capacity of tomato (Solanum lycopersicum $\mathrm{L}$.) fruit during storage. Postharvest Biol. Technol. 76:119-124.
Ali, A., M. Maqbool, S. Ramachandran, and P.G. Alderson. 2010. Gum arabic as a novel edible coating for enhancing shelf-life and improving postharvest quality of tomato (Solanum lycopersicum L.) fruit. Postharvest Biol. Technol. 58:42-47.

Allende, A., Y. Luo, J. McEvoy, F. Artés, and C. Wang. 2006. Microbial and quality changes in minimally processed baby spinach leaves stored under super atmospheric oxygen and modified atmosphere conditions. Postharvest Biol. Technol. 33:51-59.

Arnon, D.I. 1949. Copper enzymes in isolated chloroplasts. Polyphenolxidase in Beta vulgaris. Plant Physiol. 24:1-15.

Artes, F., F. Vallejo, and J. Martinez. 2001. Quality of broccoli as influenced by film wrapping during shipment. Eur. Food Res. Technol. 213(6):480-483.

Barazani, O., A. Perevolotsky, and R. Hadas. 2008. A problem of the rich: Prioritizing local plant genetic resources for ex situ conservation in Israel. Biol. Conserv. 141(2):596-600.

Barros, L., A.M. Carvalho, and I.C.F.R. Ferreira. 2010. Leaves, flowers, immature fruits and leafy flowered stems of Malva sylvestris: A comparative study of the nutraceutical potential and composition. Food Chem. Toxicol. 48:1466-1472.

Ben-Simchon, E., E. Sapir, Y. Vaknin, and O. Shelef. 2019. Malvaceae spp. leaves as a novel crop for food. Intl. J. Agr. For. Life Sci. 3(2):279-286.

Bilen, S., O.N. Kenanoglu, E. Terzi, R.C. Ozdemir, and A.Y. Sonmez. 2019. Effects of tetra (Cotinus coggygria) and common mallow (Malva sylvestris) plant extracts on growth performance and immune response in Gilthead Sea bream (Sparus aurata) and European Sea bass (Dicentrarchus labrax). Aquaculture 512:734251.

Bottino, A., E. Degl'Innocenti, L. Guidi, G. Graziani, and V. Fogliano. 2009. Bioactive compounds 
during storage of fresh-cut spinach: The role of endogenous ascorbic acid in the improvement of product quality. J. Agr. Food Chem. 57:29252931.

Bouriche, H., H. Meziti, A. Senator, and J. Arnhold. 2011. Anti-inflammatory, free radical-scavenging, and metal-chelating activities of Malva parviflora. Pharm. Biol. 49(9):942-946.

Bunea, A., M. Andjelkovic, C. Socaciu, O. Bobis, M. Neacsu, R. Verhe, and J. Van Camp. 2008. Total and individual carotenoids and phenolic acids content in fresh, refrigerated and processed spinach (Spinacia oleracea L.). Food Chem. 108:649-656.

Cao, S., Y. Zheng, and Z. Yang. 2011. Effect of 1-MCP treatment on nutritive and functional properties of loquat fruit during cold storage. N. Z. J. Crop Hort. Sci. 39(1):61-70.

Castellanos, D.A. and A.O. Herrera. 2017. Modified atmosphere packaging: Design and optimization strategies for fresh produce, p. 85-106. In: $\dot{\mathrm{I}}$. Kahramanoğlu (ed.). Postharvest handling, InTech Open, London.

Chen, J., Y. Shen, C. Chen, and C. Wan. 2019. Inhibition of key citrus postharvest fungal strains by plant extracts in vitro and in vivo: A review. Plants 8(2):26.

Cooper, M.R. and A.W. Johnson. 1984. Poisonous plants in Britain and their effects on animals and man. Michigan University, H.M. Stationery Office, London, UK.

Escalone, V.H., E. Aguayo, G.B. Martinez-Hernandez, and F. Artez. 2010. UVC doses to reduce pathogen and spoilage bacterial growth in vitro and in baby spinach. Postharvest Biol. Technol. 56:223-231.

FAO. 2020. The state of food security and nutrition in the world. 21 Mar. 2020. <http://www.fao.org/ hunger/en/>.

Fonseca, S.C., F.A.R. Oliveira, and J.K. Brecht. 2002. Modelling respiration rate of fresh fruits and vegetables for modified atmosphere packages: A review. J. Food Enginer. 52:99-119.

Food Plant Solutions. 2016. Bruce French. 21 Mar. 2020. $<$ https://foodplantsolutions.org/bruce-french/>

Garcia-Sotelo, D., B. Silva-Espinoza, M. PerezTello, I. Olivas, E. Alvarez-Parrilla, G.A. González-Aguilar, and J.F. Ayala-Zavala. 2019. Antimicrobial activity and thermal stability of rosemary essential oil: $\beta$-cyclodextrin capsules applied in tomato juice. Lebensm. Wiss. Technol. 111:837-845.

Glowacz, M., L.M. Mogren, J.P.H. Reade, A.H. Cobb, and J.M. Monaghan. 2013. Can hot water treatments enhance or maintain postharvest quality of spinach leaves? Postharvest Biol. Technol. 81:23-28.

Gogo, E.O., N. Förster, D. Dannehl, L. Frommherz, B. Trierweiler, A.M. Opiyo, Ch. Ulrichs, and S. Huyskens-Keil. 2018. Postharvest UV-C application to improve health promoting secondary plant compound pattern in vegetable amaranth. Innov. Food Sci. Emerg. 45:426-437.

Gómez, F., L. Fernandez, G. Gergoff, J.J. Guiamet, A. Chaves, and C.G. Bartoli. 2008. Heat shock increases mitochondrial $\mathrm{H} 2 \mathrm{O} 2$ production and extends postharvest life of spinach leaves. Postharvest Biol. Technol. 49:229-234.

Grozeff, G.E., A.R. Chaves, and C.G. Bartoli. 2013. Low irradiance pulses improve postharvest quality of spinach leaves (Spinacia oleraceae L. cv Bison). Postharvest Biol. Technol. 77:35-42.

Gutiérrez-Martínez, P., A. Ramos-Guerrero, C. Rodríguez-Pereida, L. Coronado-Partida, J. Angulo-Parra, and R. González-Estrada. 2018. Chitosan for postharvest disinfection of fruits and vegetables, p. 231-241. In: M.W. Siddiqui (ed.). Postharvest disinfection of fruits and vegetables. CRC Press, Boca Raton, FL.
Han, P., M. Mohebbi, H.S. Seo, and T. Hummel. 2020. Sensitivity to sweetness correlates to elevated reward brain responses to sweet and high-fat food odors in young healthy volunteers. Neuroimage 208:116413.

Hong, P., W. Hao, J. Luo, S. Chen, M. Hu, and H. Zhong. 2014. Combination of hot water, Bacillus amyloliquefaciens HF-01 and sodium bicarbonate treatments to control postharvest decay of mandarin fruit. Postharvest Biol. Technol. 88:96-102.

Imahori, Y., J. Bai, and E. Baldwin. 2016. Antioxidative responses of ripe tomato fruit to postharvest chilling and heating treatments. Scientia Hort. 198:398-406.

IRDC. 2010. Facts and figures on food and biodiversity. 21 Mar. 2020. < https://www.idrc.ca/ en/research-in-action/facts-figures-food-andbiodiversity?

Kahramanoğlu, İ. 2017. Introductory chapter: Postharvest physiology and technology of horticultural crops, p. 1-5. In: İ. Kahramanoğlu (ed.). Postharvest handling, InTech Open, London.

Kahramanoğlu, İ. 2019. Effects of lemongrass oil application and modified atmosphere packaging on the postharvest life and quality of strawberry fruits. Scientia Hort. 256, doi: 10.1016/j. scienta.2019.05.054.

Kahramanoğlu, İ. and S. Usanmaz. 2019. Improving postharvest storage quality of cucumber fruit by modified atmosphere packaging and biomaterials. HortScience 54:2005-2014.

Kahramanoğlu, İ, C. Chen, J. Chen, Z. Gan, and C. Wan. 2020. Improving storability of 'Nanfeng' mandarins by treating with postharvest hot water dipping. J. Food Qual. doi: 10.1155/ 2020/8524952.

Kahramanoğlu, İ., M. Aktaş, and Ş. Gündüz. 2018. Effects of fludioxonil, propolis and black seed oil application on the postharvest quality of "Wonderful” pomegranate. PLoS One 13(5):e0198411, doi: 10.1371/journal.pone.0198411.

Kang, Y., S. Khan, and X. Ma. 2009. Climate change impacts on crop yield, crop water productivity and food security - A review. Prog. Nat. Sci. 19:1665-1674.

Kasim, M.U. and R. Kasim. 2008. Double-sided UV-C treatments delayed chlorophyll degradation but increased chilling injury of green bean (Phaseolus vulgaris L. cv. Helda) during storage. J. Food Agr. Environ. 6(3/4):176-180.

Kasim, M.U. and R. Kasim. 2017. Yellowing of fresh-cut spinach (Spinacia oleracea L.) leaves delayed by UV-B applications. Inf. Process. Agr. 4:214-219.

Lai, T., X. Bai, Y. Wang, J. Zhou, N. Shi, and T. Shou. 2015. Inhibitory effect of exogenous sodium bicarbonate on development and pathogenicity of postharvest disease Penicillium expansum. Scientia Hort. 187:108-114.

Lal, R. 2005. Climate change, soil carbon dynamics, and global food security, p. 113-143. In: R. Lal, N. Uphoff, B.A. Stewart, and D.O. Hansen (eds.). Climate change and global food security. CRC Press, Boca Raton, FL.

Lichtenthaler, H.K. and C. Buschmann. 2001. Chlorophylls and carotenoids: Measurement and characterization by UV-VIS spectroscopy. Current Protocols in Food Analytical Chemistry 1:F4.3.1-F4.3.8.

Martínez-Sánchez, A., P. Lozano-Pastor, F. ArtésHernándeza, F. Artésa, and E. Aguayoa. 2019. Preharvest UV-C treatment improves the quality of spinach primary production and postharvest storage. Postharvest Biol. Technol. 155: 130-139.

Martins, C.A.F., M.L. Campos, A.C. Irioda, D.P. Stremel, A.C.L.B. Trindade, and R. Pontarolo.
2017. Anti-inflammatory effect of Malva sylvestris, Sida cordifolia, and Pelargonium graveolens is related to inhibition of prostanoid production. Molecules 22(11):1883.

Michalak, D. 2020. Adapting to climate change and effective water management in Polish agriculture - At the level of government institutions and farms. Ecohydrol. Hydrobiol. 20(1):134 141.

Motlagh, S., P. Ravines, K.A. Karamallah, and Q. Ma. 2006. The analysis of Acacia gums using electrophoresis. Food Hydrocoll. 20:848-854.

Ncama, K., L.S. Magwaza, A. Mditshwa, and S.Z. Tesfay. 2018. Plant-based edible coatings for managing postharvest quality of fresh horticultural produce: A review. Food Packag. Shelf Life 16:157-167.

Nikkhah, M. and M. Hashemi. 2020. Boosting antifungal effect of essential oils using combination approach as an efficient strategy to control postharvest spoilage and preserving the jujube fruit quality. Postharvest Biol. Technol. 164:111159.

Papoutsis, K., M.M. Mathioudakis, J.H. Hasperuéd, and V. Ziogas. 2019. Non-chemical treatments for preventing the postharvest fungal rotting of citrus caused by Penicillium digitatum (green mold) and Penicillium italicum (blue mold). Trends Food Sci. Technol. 86:479-491.

Plestenjak, A., T. Pozrl, J. Hribar, T. Unuk, and R. Vidrih. 2008. Regulation of metabolic changes in shredded cabbage by modified atmosphere packaging. Food Technol. Biotechnol. 46(4):427433.

Prakash, B., A. Kedia, P.K. Mishra, and N.K. Dubey. 2015. Plant essential oils as food preservatives to control moulds, mycotoxin contamination and oxidative deterioration of agri-food commodities-Potentials and challenges. Food Control 47:381-391.

Quintana, M.E.G. and R.E. Paul. 1993. Mechanical injury during postharvest handling of solo papaya fruit. J. Amer. Soc. Hort. Sci. 118:618622.

Riva, S.C., U.O. Opara, and O.A. Fawole. 2020. Recent developments on postharvest application of edible coatings on stone fruit: A review. Scientia Hort. 262:109074.

Royal Botanical Garden Report. 2017. State of the world's plants. Royal Botanic Gardens, Kew. 21 Mar. 2020. <https://stateoftheworldsplants.org/2017/report/SOTWP_2017.pdf>.

Sethi, S. 2015. Bread, wine, chocolate: The slow loss of foods we love. HarperCollins, New York.

Shelef, O., J.D. Fernández-Bayo, Y. Sher, V. Ancona, H. Slinn, and Y. Achmon. 2018. Elucidating local food production to identify the principles and challenges of sustainable agriculture, p. 47-81. In: C.M. Galanakis (ed.). Sustainable food systems from agriculture to industry. 1st ed. Elsevier Inc., London, UK.

Shen, Y., L. Zhong, Y. Sun, J. Chen, D. Liu, and X. Ye. 2012. Influence of hot water dip on fruit quality, phenolic compounds and antioxidant capacity of Satsuma mandarin during storage. Food Sci. Technol. Intl. 19(6):511-521.

Silva, I.M.B.R., R.H.C. Rocha, H.S. Silva, I.S. Moreira, F.A. Sousa, and E.P. Paiva. 2015. Quality and post-harvest life organic pomegranate 'Molar' produced in Paraiba semiarid. Semina: Ciências Agrárias 36(4):2555-2564.

Sudhakar, P., P. Latha, and P.V. Reddy. 2016. Chapter 15 - Plant pigments, p. 121-127. In: P. Sudhakar, P. Latha, and P.V. Reddy (eds.). Phenotyping crop plants for physiological and biochemical traits. Academic Press, Elsevier Inc. 
Tudela, J.A., A. Marin, Y. Garrido, M. Cantwell, M.S. Medina-Martinez, and M.I. Gil. 2013. Off-odour development in modified atmosphere packaged baby spinach is an unresolved problem. Postharvest Biol. Technol. 75:75-85.

Warren, J. 2015. The nature of crops - How we came to eat the plants we do. Aberystwyth University, Wales, UK.

Xin, Z., Q.O. Yang, C. Wan, J. Che, L. Li, J. Chen, and N. Tao. 2019. Isolation of antofine from Cynanchum atratum BUNGE (Asclepiadaceae) and its antifungal activity against Peni- cillium digitatum. Postharvest Biol. Technol. 157:110961.

Yao, Y., Y. Yang, J. Ren, and C. Li. 2006. UVspectra dependence of seedling injury and photosynthetic pigment change in Cucumis sativus and Glycine max. Environ. Exp. Bot. 57:160-167.

Yarijani, Z.M., H. Najafi, D. Shackebaei, S.H Madani, M. Modarresi, and S.V. Jassemi. 2019. Amelioration of renal and hepatic function, oxidative stress, inflammation and histopathologic damages by Malva sylvestris extract in gentamicin induced renal toxicity. Biomed. Pharmacother. 112:108635.

Zhang, Y.F., Y.P. Li, J. Sun, and G.H. Hang. 2020. Optimizing water resources allocation and soil salinity control for supporting agricultural and environmental sustainable development in Central Asia. Sci. Total Environ. 704:135281.

Zhao, X., M. Xia, X. Wei, C. Xu, Z. Luo, and L. Mao. 2019. Consolidated cold and modified atmosphere package system for fresh strawberry supply chains. Lebensm. Wiss. Technol. 109:207-215. 